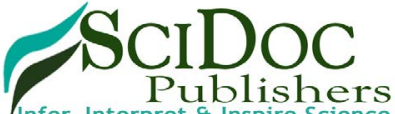

Publishers

International Journal of Anesthesiology \& Research (IJAR)

ISSN 2332-2780

\title{
Magnitude and Associated Risk Factors of Post-Operative Sore Throat Following Surgery by General Anesthesia with Endotracheal Intubation in Black Lion Hospital, Addis Ababa, Ethiopia
}

Research Article

Birhanu Mengistu $\mathrm{S}^{1}$, Akalu L $2^{2}$

${ }^{1}$ Health Sciences Faculty, Department of Anesthesia, Jimma, Ethiopia.

${ }^{2}$ Health Sciences Faculty, School of Anesthesia, Addis Ababa University, Addis Ababa, Ethiopia.

\section{Abstract}

Background: A complaint of postoperative pharyngeal discomfort is so prevalent that it is almost expected by patients and anesthetist alike as an unavoidable part of routine anesthesia. Complaints range from a minor throat irritation to debilitating pain, inability to swallow and temporary voice changes, and are a frequent observation on the postoperative visit. There is no data regarding the magnitude of post-operative airway complications and their associated risk factors in Ethiopia.

Objective: The purpose of this study is to assess the magnitude and possible associated risk factors for postoperative sore throat following surgery by general anesthesia with endotracheal intubation.

Methods and Materials: Institutional based crossectional study design was conducted in Black Lion Hospital, Addis Ababa, Ethiopia from February 1-30, 2016 in patients aged 18 years and above who underwent surgery under anesthesia with endotracheal intubation using structured questionnaire prepared on variables being measured. Bivariate analysis and binary logistic regression was used to measure association between dependent and independent variables. P value 0.05 was used as cut off point.

Results: Out of 114 patients who had elective surgery by anesthesia with endotracheal intubation, 52(45.6\%) of the study participants complained of various forms of post-operative throat complaints. In this study it was found that size of ETT showed statistically significant association with the post-operative sore throat with p-value 0.001 , (AOR- 0.214, 95\% CI 0.090-0.512) and the duration of anesthesia/surgery also showed statistically significant association with POST with p-value 0.014, (AOR 0.14, 95\% CI 0.029-0.676).

Conclusion and Recommendation: The findings of this study confirmed previous observations that the larger the ETT size, the higher the incidence of postoperative respiratory morbidities. Although tracheal intubation remains an absolute necessity for good airway protection for different surgical procedures, we recommended to use the smaller ETT sizes (6.5, $7.0 \mathrm{~mm}$ ID) to minimize the pressure-induced trauma on the laryngeal and tracheal mucosae.

Keywords: Post Operative Sore Throat; Endotracheal Tube; Surgery; Black Lion Hospital.

\section{Introduction}

Despite recent advances in anaesthesia and surgery, major surgical operations are still beset with undesirable postoperative sequelae. These represent a significant negative aspect of surgical care, which may in no small way diminish patients' confidence in the healthcare. The respiratory system is particularly vulnerable when general anaesthesia with endotracheal intubation is used. This is because the conduct of this technique of anaesthesia often involves interference with the normal airway mucosal barrier mechanisms by way of instrumentation, or interference with the normal mucosal or ciliary activities due to inhalation of unhumidified anaesthetic gases. The interference, in many cases, may lead to trauma, foreign body contamination, mucosal dryness and airway irritation, which manifest in various ways in the postoperative period [1-3].

The etiology of POST is also not clearly understood, but it appears to be an inflammatory process since the tracheal mucosa has been found to release inflammatory mediators after intuba-

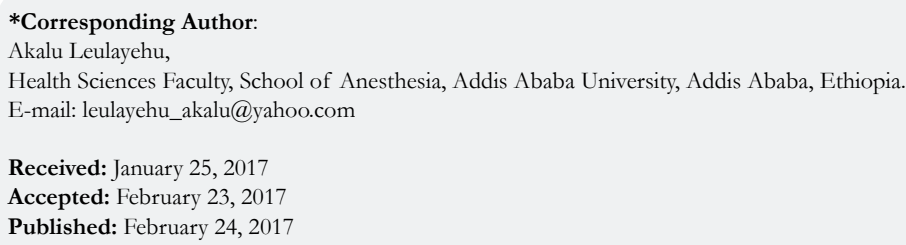

Citation: Birhanu Mengistu S, Akalu L (2017) Magnitude and Associated Risk Factors of Post-Operative Sore Throat Following Surgery by General Anesthesia with Endotrachea Intubation in Black Lion Hospital, Addis Ababa, Ethiopia. Int J Anesth Res. 5(2), 409-413. doi: http://dx.doi.org/10.19070/2332-2780-1700084

Copyright: Akalu $\mathbf{L}^{\oplus}$ 2017. This is an open-access article distributed under the terms of the Creative Commons Attribution License, which permits unrestricted use, distri bution and reproduction in any medium, provided the original author and source are credited. 
tion. However, the exact anatomical location of sore throat still remains uncertain in patients [7].

The incidence of postoperative sore throat (POST) varies from $0-50 \%$ in most research studies, but some report the incidence is as high as $51-88.4 \%$ following general anesthesia. The high variability is due to a large number of factors implicated in POST such as type and size of airway device, technique of insertion, use of lubricant, airway design, cuff pressure, length of procedure, anesthesia administered, evaluation techniques, and a multitude of patient features. Regardless of the incidence or duration, POST is rated as a patient's $8^{\text {th }}$ most undesirable outcome in the postoperative period, and is certainly an opportunity to improve patient outcomes $[1,3,10,11]$.

There is no any research available for healthcare providers that assess the incidence and its associated risk factors of POST in Ethiopia. Therefore, this study is aimed at clearly assessing the most common factors associated with POST and its incidence in Ethiopia. Awareness of the variables associated with an increased incidence of POST will allow health care providers to minimize combinations of risk factors, reduce the incidence and severity of POST, and improve a patient's anesthesia experience.

\section{Materials and Methods}

\section{Study Area and Period}

This study was conducted in Black Lion Hospital, which is found in Addis Ababa, Ethiopia, and is one of the teaching hospitals of Addis Ababa University. The study was conducted from February 1-30, 2016.

\section{Study Design}

Institutional based cross sectional study design was employed.

\section{Population}

Source population: All adult patients who undergone surgery under general anesthesia with endotracheal intubation.

Study population: Selected patients who undergone surgery under general anesthesia with endotracheal intubation in the specified period.

\section{Inclusive and Exclusive Criteria}

Inclusion criteria: patients with age 18 and above.

Exclusion criteria: was surgery performed in the mouth or throat area, patients with upper airway infections and cesarean delivery as well as emergency procedures are not included.

\section{Sample Size and Sampling Technique}

All the patient who undergone surgery by anesthesia with endotracheal intubation in the specified period was included.

\section{Study Variables}

Independent: Age, sex, diagnosis, duration of anesthesia, ETT size, number of attempts during laryngoscopy, use of airways, use of NG tube and insertion of throat pack.

\section{Data Collection Technique and Instrument}

Data was collected using questionnaires prepared in English and then translated to Amharic. Data was collected by four MSc. in anesthesia students and follow up was made for every patient post operatively for at least 24 hours. The study tools include the type of airway device used, number of attempts during laryngoscopy to intubate the trachea, size of ETT employed, duration of anesthesia, demographic variables and overall medical condition of the patients will be observed.

\section{Data Quality Control}

- Training and orientation about the objective and process of data collection was provided for data collectors.

- Close supervision and follow up was made during the data collection.

\section{Data Analysis and Interpretation}

After collection, data was summarized and coded. Data was entered in to epi info version 7 and transported to SPSS version 20.0 for data cleaning up and analyzing. Proportions was calculated for all categorical variables, bivariate analysis was done for each independent variables with dependent variable and binary logistic regression was done to measure association between dependent and each independent variables while controlling other variables. $\mathrm{P}$ value and 95\% C.I was used to judge significant of association. P-value 0.05 was used as cut off point.

\section{Operational Definition}

1. Endotracheal tube (ETT): is a specialized device used for airway maintenance.

2. Endotracheal intubation: a technique used for airway maintenance by which a tube is inserted to trachea through mouth or nose.

3. Laryngoscopy: is a technique of using a device called laryngoscope to view laryngeal structures to facilitate endotracheal intubation.

\section{Ethical Consideration}

After approval of the proposal, ethical clearance was obtained from the Ethical review committee of department Anesthesia medical faculty, School of medicine, AAU and letter was given to Addis Ababa health bureau Black Lion Hospital for support and permission. Informed verbal consent was obtained from respondents after giving them information about the study. In addition, all the responses were kept confidential and anonymous.

\section{Dissemination Plan}

The copies of final results will be disseminated to college of health science and medicine, Hospitals and health centers in Addis Ababa, Addis Ababa Health Bureau and Federal Ministry of Health, Ethiopian association of anesthetists. Relevant develop- 
ment oriented or extension institutions will be informed about the findings of the study through manuals, brochures and leaflets. It will be published in local as well as multi national and international languages. It will be presented on workshop and different seminar.

\section{Results and Discussion}

The study was conducted on 114 patients. The patients included in this study were adults aged 18 and above. The mean age of the study subjects was $37.71 \pm 15.001 \mathrm{SD}$ with minimum 18 , maximum 73. The study showed majority of the subjects were aged 18-60. Out of the patients who developed post-operative throat complaints $\mathrm{N}=47(90.4 \%)$ were aged between 18 and 60 years of age and $\mathrm{N}=5(9.6 \%)$ of the study subjects were aged above 60 years of age.

In this study there was no significant association between age and occurrence of POST. A study conducted in Watford General Hospital, United Kingdom, also showed no significant difference in the incidence of sore throat between the age groups studied [18]. But according to a prospective, cross-sectional study carried out at the University Hospital in Orebro, Sweden, from March to December 2008, age greater than 60 years was found to be significantly associated with development of POST compared with 18 to 60 years [5].

In this study the sizes of ETT used ranged from 6.0 to 7.5. The size number 6.5 was the mostly used endotracheal tube during the study period with $\mathrm{N}=46(40.4 \%)$ (Table 1$)$.

The results from this study showed there is statistically significant association between size of ETT tube and occurrence of postoperative throat complaints. According to a prospective, crosssectional study carried out at the University Hospital in Orebro, Sweden, from March to December 2008, had also comparable result showing significant association between size of ETT and the development of POST. With ETT size No. 7.0 compared with ETT 6.0 (51\% vs. $27 \%$ [25/49 vs. $13 / 48]$; $\mathrm{P}=.02)$ [5]. This is because with the increasing the diameter of the ETT there is increase in tightness with the tracheal mucosa and this causes direct trauma to the tracheal mucosa and possibly results in post-operative throat complaints. The results from a double-blind, randomized-controlled study conducted in the Departments of Plastic Surgery and the Ear Nose and Throat (ENT) surgery, at the O* rebro University Hospital, Sweden has also showed the comparable result. There were a higher proportion of patients with sore throat in ET'T 7.0 vs. ETT 6.0 (51.1\% vs. 27.1\%), P50.006 [11].

Number of attempts at laryngoscopy during the endotracheal intubation ranged from single attempt to four attempts. The study showed that $\mathrm{N}=80(70.2 \%)$ of the patients are intubated with the single attempts at laryngoscopy. But only $\mathrm{N}=1(0.9 \%)$ of patient was intubated after four attempts at laryngoscopy (Table 2).

The results from this study showed no significant association between the POST and number of attempts during the tracheal intubation. The study conducted by Christensen AM, et al., also showed multiple attempts at intubation did not increase the incidence of sore throat [1], a prospective study by Kolawole and Ishaqwas was also found no statistical significance association between number of attempts at laryngoscopy and POST [16]. Another study conducted in Watford General Hospital had similar result showing no statistically significant association between the POST and multiple attempts at laryngoscopy [18]. Even though the number of attempts was not an independent predictor of the occurrence of POST, it causes direct trauma to the larynx and there is possibility of developing pain in the throat in the postoperative period.

The duration of anesthesia and surgery in the study was ranged from 1 - 12 hours with mean duration of $2.98 \pm 1.872$. In the study period the minimum duration that the patients stayed under anesthesia was 1 hour and the max. was 12 hours. This study also showed that $\mathrm{N}=96(84.2 \%)$ of the patients stayed more than 90 minutes under anesthesia (Figure 1).

This study has shown significant association between duration of

Table 1. The Frequency of the Size of ETT used During the Study Period in Black Lion Hospital, Addis Ababa, Ethiopia, from Feb. 1-30, 2016.

\begin{tabular}{|c|c|c|c|}
\hline Size of ETT & Frequency & Percent & Cumulative Percent \\
\hline 6.0 & 4 & 3.5 & 3.5 \\
\hline 6.5 & 46 & 40.4 & 43.9 \\
\hline 7.0 & 19 & 16.7 & 60.5 \\
\hline 7.5 & 45 & 39.5 & 100.0 \\
\hline Total & 114 & 100.0 & \\
\hline
\end{tabular}

Table 2. The Frequency of the Number of Attempts at Laryngoscopy During the Endotracheal Intubation in the Study Period in Black Lion Hospital, Addis Ababa, Ethiopia, from Feb. 1-30, 2016.

\begin{tabular}{|c|c|c|}
\hline Number of Attempts & Frequency & Percent \\
\hline 1 & 80 & 70.2 \\
\hline 2 & 30 & 26.3 \\
\hline 3 & 3 & 2.6 \\
\hline 4 & 1 & 0.9 \\
\hline Total & 114 & 100.0 \\
\hline
\end{tabular}


Figure 1. The Percentage of the Duration of Anesthesia in the Study Group in Black Lion Hospital, Addis Ababa, Ethiopia from Feb. 1-30, 2016.

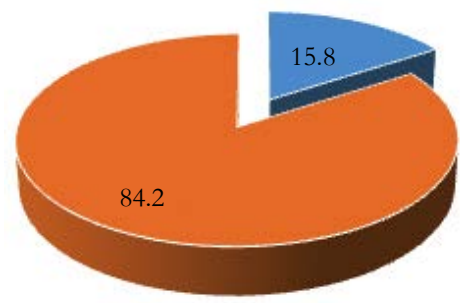

$m</=1.5=>1.5$

anesthesia and/or surgery more than 60 minutes and the development of POST. The study conducted by Ahmed et al., to evaluate the factors associated with an increased incidence of POST had comparable result showing increased incidence of developing post-operative sore throat with the increased duration of surgery [12]. Another study conducted by Edomwonyi, et al., also showed the duration of anesthesia greater than 60 minutes did correlate with an increased incidence of POST [14]. A randomized, prospective, and observational study conducted in 4 tertiary care university hospitals in Shanghai, China also shown comparable result to the above studies. The reason behind could possibly be, as there is increased duration of anesthesia and or surgery the patient will be intubated for long period especially if the tube is tight fitting the resulting compression on the mucosa of the trachea result in the associated pain during the post-operative period.

This study had shown no statistical significance to the occurrence of post-operative throat complaints and the use of the airway adjuvants (i.e. oropharyngeal airway, nasogastric tube and throat pack). But the prospective, cross-sectional study carried out at the University Hospital in Orebro, Sweden, from March to December 2008, found statistically significant association between the use of throat pack and POST [5]. The study conducted by Edomwonyi, et al., shows the associated use of nasogastric tubes or throat packing resulted in increased complaints of POST [13]. Christensen AM, et .al., also found association between POST and the presence of a nasogastric tube [15]. But the result of this study may be due to the limited utilization of this devices in the study.

\section{Acknowledgement \& Declarations}

Firstly, I would like to acknowledge the Addis Ababa University for giving me the chance to prepare this research paper.

My next gratitude will go to Mr. Leulayehu Akalu for giving me priceless advices and constructive comments in the preparation of this research paper.

I undersigned declare that this student research paper is my original work and all the materials used for this study have been duly acknowledged.

\section{Conclusion and Recommendation}

The findings of this study confirmed previous studies $[5,12]$ that the larger the ETT size, the higher the incidence of postoperative respiratory morbidities. This is possibly due to the trauma in- duced by tight fitting ETT's. Although tracheal intubation remains an absolute necessity for good airway protection for different surgical procedures, it is recommended to use the smaller size ETTs $(6.5,7.0 \mathrm{~mm}$ ID) to minimize the pressure-induced trauma on the laryngeal and tracheal mucosae. It is recommended that the administration of the Black Lion Hospital could provide enough amount of ETT in range of sizes so as to help anesthetists to choose appropriate size for individual patients.

The prolonged duration of anesthesia and surgery had increased the risk of developing post-operative throat complaints as also signified by another studies [14]. It could be advisable to perform surgeries as much as in smaller time possible and using smaller size ETT for airway maintenance could reduce the risk of developing the POST.

Even though this study didn't show statistically significant association between the number of attempts at laryngoscopy and POST, it is still wise to be able to reduce the number of attempts during tracheal access, because it is obvious that with multiple attempts there is damage to mucosa around the larynx by direct trauma due to instrumentation during laryngoscopy.

We recommend further studies in this area to evaluate the association between the practitioner experience, use of another airway maintenance devices like LMA's and the post-operative throat complaints. And also on management of the patients who complained of post-operative throat pain.

\section{References}

[1]. Baker AB (2011) Factors Affecting the Incidence of Sore Throat Following General Anesthesia with Endotracheal Tube Versus Laryngeal Mask Airway. J Texas Christian University. 50(2): 13-25.

[2]. Lisa Zuccherelli (2003) Postoperative upper airway problems. South Afri J Anaesthesia Analgesia. 3: 12-16.

[3]. kolawoleik, ishaq MS (2008) Post-anaesthetic respiratory complaints following endotracheal anaesthesia in lower abdominal obstetric and gynecology surgery. Niger J Clin Pract. 11(3): 225-230.

[4]. Thang'a P, Kamya D, Mung'ayi V (2013) Effects of intravenous diclofenac on postoperative sore throat in patients undergoing laparoscopic surgery at Aga Khan University Hospital , Nairobi: A prospective, randomized, double blind controlled trial. Afr Health Sci. 13(4): $999-1006$.

[5]. Maria Jaensson, Anil Gupta, Ulrica G Nilsson (2012) Risk factors for development of postoperative sore throat and hoarseness after endotracheal intubation in women: A Secondary Analysis. AANA J. 80(4): 67-73.

[6]. Dipanjan Bagchi D, Mandal MC, Das S, Sahoo T, Basu SR, et al., (2012) Efficay of Intravenous dexamethasone to reduce postoperative sore throat: A prospective randomized controlled trial. J Anesthesiol Clin Pharmacol. 28(4): 477-480.

[7]. Jaensson M, Gupta A, Nilsson U (2014) Gender differences in sore throat 
and hoarseness following endotracheal tube or laryngeal mask airway: a prospective study. BMC Anesthesiol. 14: 56.

[8]. Kiran S, Goel M, Singhal P, Gupta N, Bhardwaj M (2012) Postoperative sore throat with $0.05 \%$ betamethasone gel and $2 \%$ lignocaine jelly used as a lubricant for ProSeal LMA (PLMA) insertion. Egypt J Anaesthesia. 28: 139-142.

[9]. McHardy FE, Chung F (1999) Postoperative sore throat: Cause, prevention and treatment. Anaesthesia. 54(5): 444-53

[10]. Najafi A, Imani F, Makarem J, Etezadi F, Habibi S, et al., (2014) Postoperative Sore Throat after Laryngoscopy with Macintosh or Glide Scope Video Laryngoscope Blade in Normal Airway Patients. Anesth Pain Med. 4(1): e15136.

[11]. Jaensson M, Olowsson LL, Nilsson U (2010) Endotracheal tube size and sore throat following surgery: A randomized-controlled study. Acta Anaesthesiol Scand. 54(2): 147-153.

[12]. Ahmed A, Abbasi S, Ghafoor H, Ishaq M (2007) Postoperative sore throat after elective surgical procedures. J Ayub Med Coll Abbottabad. 19(2): 1214.
[13]. Edomwonyi NP, Ekwere IT, Omo E, Rupasinghe A (2006) Postoperative throat complication after tracheal intubation. Ann Afr Med. 5: 28-32.

[14]. Christensen AM, Willemoes-Larsen H, Lundby L, Jakobsen KB (1994) Postoperative throat complaints after tracheal intubation. Br J Anaesth. 73(6): 786-787.

[15]. Liu J, Zhang X, Gong W, Li S, Wang F, et al., (2010) Correlations between Controlled Endotracheal Tube Cuff Pressure and Post procedural Complications. Anesth Analg. 111(5): 1133-7.

[16]. Higgins PP, Chung F, Mezei G (2002) Postoperative sore throat after ambulatory surgery. Br J Anaesth. 88(4): 582-584.

[17]. Biro P, Seifert B, Pasch T (2005) Complaints of sore throat after tracheal intubation: a prospective evaluation. Eur J Anesthesiol. (4): 307-311.

[18]. Kloub R (2001) Sore throat following tracheal intubation. Middle East J Anesthesiol. 16(1): 29-40.

[19]. Kadri IA, Khanzada TW, Samad A, Memon W (2009) Post-thyroidectomy sore throat: A common problem. Pak J Med Sci. 25(3): 408-412.

[20]. Karen B Domino, Karen L, Cheny FW, Caplan RA (1999) Airway Injury during Anesthesia: a closed claims analysis. Anesthesiology. 91(6): 1703-11. 